Giupponi, Germán: "Los Cursillos de Cristiandad. Un movimiento católico comunitario"; en REA, No XXIII, 2017; Escuela de Antropología - FHUMYAR UNR; pp. 191-208.

\title{
Los Cursillos de Cristiandad. Un movimiento católico comunitario
}

\author{
Germán Giupponi \\ Universidad Nacional del Litoral \\ CONICET \\ germangiupponi@gmail.com
}

\section{Resumen}

El artículo se enfoca en los Cursillos de Cristiandad, un movimiento católico que altera históricamente a la cúpula de la institución. La pregunta planteada es qué aspectos que configuran las socializaciones constitutivas de los Cursillos pueden convertirse en retos eclesiales. El enfoque utilizado es una aproximación etnográfica a los Cursillos de Santa Fe y el análisis del discurso de sus protagonistas sobre esas socializaciones. La inferencia derivada es que uno de los aspectos que las configuran y que pueden convertirse en retos eclesiales es su "comunitarismo".

\section{Palabras claves}

Cursillos de Cristiandad - Movimientos católicos - Retos eclesiales - Comunitarismo

\section{The Christianity Courses. A community catholic movement}

\begin{abstract}
The article focuses on Christianity Courses, a catholic movement that historically alters the dome of the institution. The question posed is which aspects that shape the constitutive socializations of Courses can become ecclesiastical challenges. The approach selected is an ethnographical approximation to Courses of Santa Fe and the speech analysis of its main actors about those socializations. The derivative inference is that one of the aspects that shape them and that can become ecclesiastical challenges is their "community".
\end{abstract}

\section{Keywords:}

Christianity Courses, catholic movements, ecclesiastical challenges, community 
GiUPPonI, Germán - “'Los Cursillos de Cristiandad...”

\section{Los retos eclesiales de los Cursillos de Cristiandad}

Los "movimientos eclesiales" han dejado y continúan dejando una marca en la cúpula de la institución católica'. Gran parte de los movimientos expandidos en el mundo alteraron o alteran al Vaticano; lo cual queda claro en que aquellos ya admitidos por él lo fueron mucho después de sus fundaciones, y en que otros aún no lo son. Los 129 ya legalizados por la Curia Romana lo han sido varias décadas más tarde de sus inicios; y muchos todavía ni siquiera están oficializados, al carecer de la aprobación de sus estatutos mundiales por el Dicasterio para los Laicos, la Familia y la Vida (Suárez, 2014).

Entre los movimientos católicos ya acogidos en la Iglesia, al menos hay uno que incomoda históricamente a su jerarquía: el "Movimiento de Cursillos de Cristiandad". La perturbación histórica de los Cursillos de Cristiandad al clero se visibiliza no solo en que su reglamento internacional fue autorizado pasados siete decenios de su origen; sino también en que sus prácticas pioneras fueron cesadas a pocos años de ser impulsadas; y en que lo que hoy está reconocido no es su entramado en sí, sino el aparato que los administra en el mundo. Nacieron en España, en Mallorca, en la década de 1940. Desde allí, se difundieron a 58 países, incluyendo a la Argentina, a donde se propagaron por Lomas de Zamora, en $1958^{2}$. Pero sus primeras obras fueron detenidas por el nuevo obispo

1. Este trabajo se encuadra en una línea de investigación sobre los "movimientos eclesiales", conformada con la tesis propia de Licenciatura en Sociología en la Universidad Nacional del Litoral; y continuada mediante el proyecto personal de Beca Interna Doctoral del Consejo Nacional de Investigaciones Científicas y Técnicas, desarrollado como Doctorando en Antropología en la Universidad Nacional de Rosario

2. La primera experiencia en Buenos Aires no tuvo éxito y fue cesada después de su primer cursillo. Recién en 1962, en Tucumán, los Cursillos argentinos comenzaron a tener continuidad. Provenientes de los Cursillos españoles de Tarragona y Gerona, a su vez originados en los mallorquines; los tucumanos abonarán a los de Santiago del Estero; que, por su parte, irán nutriendo a los de Corrientes, Paraná y Resistencia. En paralelo, desde 1964 y Córdoba, se fue asentando otra vertiente de los Cursillos en el país. Sus raíces arraigaron tanto en los Cursillos de Tucumán 
de Mallorca, Jesús Enciso Viana, ya en 1956. El decreto de su reconocimiento canónico definitivo fue promulgado por el entonces Consejo Pontificio para los Laicos recién en el 2014. Y lo que hoy en día está contemplado por esa norma eclesial es su Organismo Mundial, y no su seno en sí mismo.

En las ciencias sociales de la religión de la Argentina, la tensión que los movimientos católicos provocan en la cúpula de la institución ya ha sido planteada. Desde fines del siglo XX, algunas investigaciones vienen mostrando la resistencia que la jerarquía produce como respuesta a los movimientos. Entre ellas, sobresale un estudio inicial, que enfatiza el recelo temprano de los obispos argentinos a la Renovación Carismática Católica; a la cual le adjudicaron implicar tanto beneficios como peligros para la Iglesia (Soneira, 1999). También se destaca un trabajo más reciente, que acentúa el resquemor actual de los sacerdotes del país a la Comunidad Mundial para la Meditación Cristiana; a la que le atribuyen acarrear riesgos para el ámbito cristiano, por combinar la meditación inherente a él con la propia de otros escenarios religiosos (Ludueña, 2014).

Lo que no se encuentran son indagaciones que aborden la tirantez que específicamente los Cursillos de Cristiandad ocasionan en la cúpula de la institución ${ }^{3}$. No se ha analizado aún cuáles son las amenazas que los Cursillos traen aparejadas para la jerarquía, que conducen a que ella desconfíe de ellos; como lo haría de la Renovación Carismática Católica o la Comunidad Mundial para la Meditación Cristiana. Pero tampoco se ha examinado todavía la cuestión más básica de cuáles son las características de los Cursillos que podrían llegar a devenir en desafíos para el clero. Se ha omitido la pregunta de qué aspectos que configuran las socializaciones constitutivas del movimiento pueden convertirse en retos eclesiales.

como en los de Caracas, Venezuela; llegando a extenderse a los de Mendoza y Pilar; y, desde ellos, a los de San Juan, La Plata y Mercedes, entre otros.

3. Aunque sí se hallan dos inquisiciones que exploran la trayectoria fundacional de los Cursillos en la Argentina (Crespo, 2007; Giorgi y Mallimaci, 2012). 
GiupPonı, Germán - “Los Cursillos de Cristiandad...”

Este trabajo busca comenzar a cubrir esa vacancia; persiguiendo avanzar, en última instancia, no solo en el conocimiento de la configuración de los Cursillos de Cristiandad; sino también en la comprensión de las relaciones establecidas en el entramado de los movimientos católicos y entre ellos y la institución católica.

La investigación que sustenta el trabajo se enfoca en una de las zonas de la Iglesia argentina en donde los Cursillos de Cristiandad se insertan: la arquidiócesis de Santa Fe. El abordaje, una aproximación etnográfica a los Cursillos santafesinos, se apoya ante todo en la observación participante de los lugares de encuentro de los protagonistas y la conversación con ellos. Los diálogos son en especial entrevistas a algunos de los involucrados, las cuales giraron alrededor de la vida cursillista de hoy, en conexión con la vivencia católica.

Los apartados principales que dividen el desarrollo del trabajo son dos. En el primero, intento exponer cómo son las socializaciones mantenidas en el seno de los Cursillos de Cristiandad de Santa Fe; explicitándolas según los sentidos declarados por sus participantes. En la segunda parte, procuro presentar cuál es el carácter de las sociabilidades sostenidas por los Cursillos santafesinos con su entorno católico; expresándolas de nuevo acorde con los significados emitidos por sus involucrados. Como conclusión, trato de arribar a una respuesta tentativa a la pregunta planteada.

\section{Las socializaciones en el seno de los Cursillos de Cristiandad de Santa Fe}

Primero, entonces, describiré los lazos entablados dentro de los Cursillos de Cristiandad de Santa Fe; analizando el discurso de seis protagonistas a quienes entrevisté en profundidad: dos insertos en ellos desde su difusión a la arquidiócesis y los otros cuatro a partir de su consolidación. Para acercarnos a una mejor comprensión de las narraciones, iré circunscribiendo las trayectorias del grupo y de los entrevistados; y también iré delimitando el contexto inherente a las entrevistas. 


\section{Los lazos en los Cursillos de Santa Fe para Pedro y Felipe}

La primera entrevista la realicé en abril del 2013, un mes después de la elección de Jorge Bergoglio como Papa de la institución católica. La Iglesia había escogido al arzobispo de Buenos Aires como el nuevo Santo Padre y mi primer informante no dejó de enfatizarlo: apenas comenzó nuestra conversación, me regaló el último número de la revista De Colores (2013) de los Cursillos de Cristiandad de Santa Fe; abocado ante todo a abordar la designación de Francisco. El nombramiento del Sumo Pontífice, no obstante, no fue el primer aspecto que emergió del contacto que entablamos. Pedro me recibió en la puerta de la sede de los Cursillos y, desde allí, me fue conduciendo por toda la casa. Lo primero que observé fue que, de todas las paredes del vestíbulo, menos de la más externa, colgaban muchos expositores de madera. Cada panel enmarcaba numerosas fotos, cada una de las cuales exponía a varias personas posando en el centro y de frente. Los fotografiados, como más tarde supe, eran todos los participantes de cada cursillo de gran parte de la historia del movimiento santafesino.

Tal como después me indicó, Pedro no había acudido como adepto a ninguno de estos retiros, sino a uno que se había realizado en la ciudad de Reconquista en 1970. Ese mismo año, ahora sí en Santa Fe, se encontró con otros laicos que antes también habían asistido como adherentes a un cursillo que se había efectuado en la ciudad de Paraná. Tras Paraná y Reconquista, los nuevos involucrados pudieron pensar en difundir el grupo a su propia arquidiócesis; y así fue que comenzaron a trabajar para lograrlo. Su intento habría contado con la colaboración de algunos sacerdotes y con la legitimación del arzobispo Vicente Zaspe. Julio Rodríguez, para la revista De Colores (2014), fue el sacerdote que recurriendo a sus contactos facilitó la bibliografía del círculo elaborada en España por sus protagonistas fundacionales ${ }^{4}$. La literatura española les habría

4. Los cursillistas fundacionales de España son los de Mallorca. Entre ellos, está quien quizás sea el protagonista más sobresaliente y discutido de la historia de los Cursillos: Eduardo Bonnín Aguiló. Bonnín es, para muchos involucrados, el laico 
GiUPPonI, Germán - “'Los Cursillos de Cristiandad...”

permitido a Pedro y a sus recientes compañeros moldear la propagación de los Cursillos a Santa Fe. Sus planificaciones se concretaron en especial con su conducción del primer retiro de la arquidiócesis, del 25 al 28 de noviembre de 1971.

-En el año '70, '71, '72, empezamos a trabajar para poder realizar el movimiento. Y, a fines de noviembre del ' 71 , se realiza el primer cursillo de Santa Fe.

-En noviembre del ' $71 \ldots$

-Paraná empezó antes que nosotros, eh...

-En Paraná antes, claro.

-Y, bueno, pero nosotros lo hicimos en una casa de retiro que se llama "El Carmen de Racedo", que está cerquita de Crespo, en la provincia de Entre Ríos.

Pedro explica que el primer cursillo de Santa Fe se realizó en la estancia Carmen de Racedo, ubicada en Entre Ríos. Allí, no ‘él' solo, ni tampoco 'él' con 'los demás', sino todos 'ellos'; consolidaron la fundación de los Cursillos santafesinos. El inicio del movimiento en la arquidiócesis no es en su discurso una cuestión de 'yo'; antes bien, es un aspecto recorrido desde el 'nosotros'. 'Nosotros, los cursillistas', es incluso un enunciado central de toda su narración, de forma más o menos explícita o implícita. Afirma, por ejemplo, que el grupo implica tres eta-

que fundó al movimiento; pero también es, según algunos otros, solo un colaborador del obispo que en verdad los inició: Juan Hervás Benet. A mediados de la década de 1950, Bonnín escribió con el sacerdote Miguel Fernández un libro, El cómo y el porqué (1971); buscando mostrar que, desde su origen, el grupo tenía su centro en Cristo. El ensayo fue publicado en 1955, el mismo año en que el Papa Pío XII trasladó a Hervás de Mallorca a Ciudad Real; eligiendo a Juan Enciso Viana como su sucesor. En 1956, Viana publicó una carta pastoral en la cual criticó con fuerza el funcionamiento del círculo y con la que, en definitiva, cesó sus prácticas pioneras. De 1956 a 1965, los Cursillos estuvieron detenidos; reanudándose a partir de la muerte de Viana y su reemplazo por Rafael Álvarez Lara. En el transcurso, en 1962, Hervás hizo público otro libro, el Manual de dirigentes de Cursillos de Cristiandad (1968); también persiguiendo exhibir que el movimiento, desde su principio, tenía su fundamento en Jesús. 
pas: un "durante" o un "retiro", un "antes" o un pre-retiro y un "después" o un pos-retiro; y, al comentar qué es el retiro, no se refiere a su propio rol en él, sino al papel de todos los participantes con trayectorias más arraigadas: "nosotros le damos cursos a la gente".

Los cursos a los cuales Pedro se remite son, justamente, los retiros alrededor de los que se va ensamblando todo el círculo; en donde los involucrados con recorridos más enraizados predican a los nuevos: les dan "rollos" o "charlas" con "testimonios" sobre la "vida cristiana", y no "clases magistrales". Cada cursillo es antecedido por un precursillo y continuado por un poscursillo. El pre-retiro es el momento en el cual los protagonistas más antiguos atraen a las personas a quienes piensan como adecuadas: lo que hacen es "precursillar" o "cautivar al posible candidato" para cada cursillo. El pos-retiro, además, es el instante en el que los cursillistas más veteranos acompañan a los recientes: los motivan a comenzar un "rodaje" o ir "profundizando" el cristianismo que experimentaron en su cursillo.

Pedro me mencionó en la entrevista a otro participante de los Cursillos de Santa Fe, con quien me contacté inmediatamente. Algunas semanas después, me encontré con mi segundo informante; aunque ya no en la sede del movimiento, sino en su lugar de trabajo. Su oficina, con el paso del tiempo, devino el sitio de muchas de las conversaciones que mantuvimos. Felipe me fue acentuando algunos aspectos del grupo, con los cuales fui profundizando otros que había dialogado con Pedro o que iba leyendo en los documentos del círculo. Entre los rasgos que Felipe me señaló, uno que sobresalió fue la administración de los Cursillos santafesinos. La gestión implica tres grandes aparatos: un cuadro conductor, o un "secretariado"; un cuerpo ejecutor, o bien, una "escuela de servicio"; y un órgano directivo de cada cursillo y de cada encuentro de revisión de este mismo retiro, llamados "equipo" de cursillo y de "jornada de metodología", respectivamente. Cada aparato, a su vez, acarrea varios roles o cuadros endógenos: el "presidente" y los "vocales" del secretariado; el "grupo rector" y los "equipos de trabajo" de la escuela 
GiUPPONI, Germán - “'Los Cursillos de Cristiandad...”

de servicio; y el "rector", las "bases" y los "auxiliares" de cada equipo de cursillo y de jornada de metodología.

Felipe, al momento de la entrevista, se desempeñaba como presidente del secretariado; quien, como me dijo, es el conductor con mayor responsabilidad del movimiento. A la máxima función de dirección del grupo, él ya la había ejercido de 1994 a 2003, para toda la Argentina; y, desde 1986 hasta 1992, para Santa Fe. En la arquidiócesis, entre 1972 y 1982, había sido el dirigente principal de otro movimiento, inspirado en los Cursillos: el "Movimiento de Encuentro de Cristiandad". El Encuentro de Cristiandad, fundado en Paraná con su colaboración, fue el círculo en donde comenzó su pos-cursillo; después de haber acudido como adepto al segundo cursillo para varones de Santa Fe, en 1972.

Los espacios que Felipe cuenta que, en general, componen el poscursillo son la "reunión de grupo" y la "ultreya". La reunión de grupo es un encuentro que se realiza en una casa o en otro lugar doméstico, entre solo algunos participantes; para compartir el día a día y a Cristo: "reflexionamos el Evangelio. Comentamos un poco nuestra vida". La ultreya, por otro lado, es la reunión en donde se juntan todos los involucrados de una zona de los Cursillos, en un sitio más amplio como su sede; a fin de reflexionar sobre el movimiento: "se da un comentar cómo vamos". Desde ocasiones así, entre otras cosas los protagonistas buscan discutir cómo atraer a nuevos cursillistas.

Anoche, justamente, tuvimos una reunión para promover más cursillos. Y había una persona que había invitado a cuarenta y tres. Cuarenta y tres personas, ¿eh? [...]. Y contaba cómo lo hacía. "Un poco así", dice. "Bueno, nosotros contamos nuestras experiencias de vida. Nosotros contamos lo que significa Cristo para nosotros, tanto en la persona, como en el matrimonio, como en la familia. Y la gente nos escucha. Y, después, por ahí, le decimos: 'mirá, hay cursillos. ¿Eh? Esto se hace en cursillos. Tenés esta fecha'". Y dice: "y esperamos que nos llame. Y, por ahí, nos llaman y nos dicen: 'che, para tal fecha, ¿podría ir al cursillo?’”.

Felipe revela que la técnica que los participantes con trayectorias 
más arraigadas utilizan en pos de captar a personas que acudan a los cursillos venideros es una estrategia interpersonal. La intimidad del recurso, no obstante, no es un rasgo que Felipe transite desde el 'yo'; sino a partir de su interpretación del testimonio de otro involucrado y a la luz del 'nosotros'. 'Nosotros, los cursillistas', es en su descripción del precursillo una frase fundamental; así como lo es en el resto de su relato. Toda la narrativa de Felipe, como la de Pedro, está atravesada de manera más o menos expresa o tácita por la primera persona del plural.

\section{Las ligaduras en los Cursillos santafesinos según María, Susana, Tomás y Julia}

En una de nuestras conversaciones, Felipe me nombró a otras dos participantes de los Cursillos de Santa Fe, con quienes me encontré en su sede. La casa del movimiento fue de nuevo el lugar en donde hallé a mis informantes y otros involucrados. Los protagonistas de los equipos de trabajo de la escuela de servicio fueron algunos de los cursillistas con quienes volví a estar frente a frente, además de mis entrevistados. María me condujo a un cuarto amoblado como para reunirse con el otro: una mesa y varias sillas lo ocupaban casi por completo, dejando poco margen para hacer otra cosa que no fuera sentarse y dialogar o actuar en común. A mi derecha, una ventana daba al vestíbulo, en donde se iban juntando quienes iban acudiendo a la sede. El salón central se llenaba rápidamente y la intensidad de los recibimientos era tal que, apenas comenzada la entrevista, tuve que preguntarle a María si podía arrimar la puerta. Pero las exclamaciones y las risas que implicaban los saludos de los recién llegados aumentaron aún más; y ni cerrando el acceso a la sala trasera en donde estábamos dejamos de escucharlas con claridad.

En esta circunstancia, entre otras cuestiones María me resaltó su entrada al grupo y su recorrido en él desde entonces. Después de 1988, tras la finalización del cursillo para mujeres al cual había asistido, desempeñó funciones en dos equipos de la escuela. La escuela, a su vez, devino la plataforma desde la cual fue convocada por el secretariado para ejercer como vocal suya, de 1995 a 1999. En el 2011, dos años 
GiupPoni, Germán - “'Los Cursillos de Cristiandad...”

antes de la entrevista, fue llamada para desempeñarse en la misma tarea. Las variadas designaciones de María en la administración del círculo la asemejan a Susana; quien tuvo cargos similares en varios períodos. E1 puesto que Susana venía ocupando antes de la entrevista, desde el 2011, era el de "secretaria" del secretariado; función que había sido antecedida por otra más, que ya había ejercido en otra de sus vocalías desde el 2000 hasta el 2003. Su ingreso al aparato administrativo de los Cursillos había ocurrido con su incorporación a un par de equipos de la escuela; luego de su misma llegada al movimiento en 1994, cuando concurrió a uno de sus retiros.

María recuerda su propio cursillo desde una de sus conductoras, en quien vio a una testigo de Dios y su amor. El cariño cristiano que la dirigente le habría brindado es algo que María primero rememora a partir del 'yo', y no a la luz del 'nosotros'. El 'nosotros', sin embargo, es el término desde el cual pasa inmediatamente a evocarla; cuando le pregunto por su experiencia con ella en términos de 'vos' y me responde en el sentido de 'nosotros, los cursillistas de aquel retiro'. La primera persona del plural es incluso la clave con la que María continúa su caracterización del cursillo en sí y de los Cursillos en general.

- ¿Y cómo la recuerda usted a esta persona, a esta auxiliar? [...].

- No, el cariño con que nos trataba. Y, bueno, y ese incondicional apoyo que te dan, ¿viste? Vos sabés que nos preparamos durante dos meses para recibir a la gente. Y, como nos preparamos en todas las virtudes, y en los valores, uno llega al cursillo, el auxiliar, en un estado de gracia muy especial, ¿no es cierto? Por eso, nosotros siempre decimos que toda la vida debería ser un estado de preparación.

Quien a su propio retiro también lo actualiza a partir de un 'yo' que se subsume en un 'nosotros' es Susana: le insinúo que me intriga saber cómo fue su vivencia de su cursillo y se para en la línea de 'yo, una cursillista'; pero, al instante, comienza a hacerlo desde el ángulo de 'nosotros, todos los cursillistas'. Es la primera persona del plural la que deviene la tónica de su reconstrucción del retiro; así como de la totalidad del movi- 
miento. Toda la reelaboración que ella y María hacen del grupo, al igual que toda la que desarrollan Pedro y Felipe, arraiga en una disposición de habla colectiva.

Yo vivía no en mi vida, sino que yo vivía como esa religión, ya te dije, de la estampita, de qué se yo, del cumplimiento. Y una cosa no asociada con la vida, la vida y la fe, que tienen que ir juntos. [...]. Nosotros decimos: "en la normalidad de la vida, en lo chiquito, en lo de todos los días, todo momento". Aunque se te sale la cadena. Cien veces nos sale la cadena. Y sabemos que tenemos que volver. Nosotros tenemos una palabra en Cursillo. Decimos: "somos inexcusables".

Después de conversar con María y Susana, a mediados del 2014 me encontré en la sede de los Cursillos de Santa Fe con otros dos participantes; a cuyos contactos también me los había dado Felipe en uno de nuestros acercamientos. Mis diálogos con los involucrados en el movimiento se profundizaban, al igual que mis observaciones de la casa en donde suelen reunirse. El edificio nuclear del grupo fue otra vez el lugar en donde acordé juntarme con uno de mis entrevistados. Tomás tuvo un imprevisto y llegó después de la hora que habíamos fijado. Mientras lo esperaba, decidí observar con mayor detenimiento las fotos que había visto enmarcadas en los expositores que colgaban de las paredes del vestíbulo. Lo que percibí, y que antes no había advertido, es que los protagonistas expuestos en todas las fotografías no solo posaban en el centro y de frente; sino también muy juntos y sumamente cerca. La postura de los cursillistas en las 205 imágenes que conté consistía en el posicionamiento del torso propio exactamente al lado del torso ajeno ${ }^{5}$.

Entre los fotografiados habrían estado Tomás, su esposa Julia y otros familiares. Su padre y su madre, según me subrayó, participan en el círculo desde hace mucho; y varias veces intentaron atraerlo, pero sin lograrlo. El éxito terminó siendo de otro involucrado, un tío suyo; quien sí pudo captarlo para que acudiera a uno de los cursillos para varones

5. La postura parece ser otra forma con la cual los cursillistas buscan, consciente o inconscientemente, exponerse como un 'nosotros'. 
que se realizaban en Santa Fe hacia el 2011. El mismo año, Julia decidió asistir a un retiro para mujeres, después de haber sido seducida por la misma familia de Tomás. Julia y Tomás, desde ese entonces, fueron convocados por el secretariado para desempeñarse como dos auxiliares de los equipos de cursillo y de jornada de metodología. Los llamados les permitieron dejar de ser solo adeptos de los Cursillos para comenzar a ser también administradores suyos. Pasaron a vivir su poscursillo tanto desde la adhesión al movimiento como a partir de su gestión.

En su rol de auxiliar del equipo del cursillo, Tomás asimila que la preparación para él se desarrolla en una atmósfera centrada en Cristo. Al clima cristiano que habría entre sus participantes lo capta a la manera de los otros entrevistados; es decir, ante todo desde el 'nosotros': "al final de una preparación, cuando estés en el retiro, llamemoslé, que es lo último que se hace antes de un cursillo; es normal que la gente diga que siente la presencia de Cristo ahí, en las personas de cada uno de nosotros".

“Nosotros, los cursillistas', y no 'yo, un cursillista'; es incluso la expresión que Tomás prioriza de modo más o menos manifiesto o supuesto para desentrañar el resto de su pos-cursillo y la totalidad de los Cursillos. Cualquier aspecto del movimiento es recuperado por él privilegiando la primera persona del plural sobre la del singular: "el ideal de nosotros es Cristo"; "nosotros somos instrumentos de lo que Él quiere hacer"; y "depende de nosotros tratar de comunicarnos con Él y dialogar con Él"; son algunas de las contestaciones que Tomás llega a darme cuando lo interrogo por su propia experiencia, y no por la de él y los demás.

Julia, al disparador de su propio pos-retiro, o a su retiro; al principio lo desgrana poniendo en primer lugar a su sentimiento de imbricación en una totalidad: "lo que más me impactó fue el encuentro con la comunidad. [...]. Yo como que me sentí tan partícipe. [...]. Yo me sentía que era parte de ese todo. Pero muy fuerte".

Al colocar por encima de todo a su sensación de integración, Julia exterioriza el 'nosotros' desde el cual hablan los demás entrevistados de una forma diferente; aunque no por esto se aleja de ellos. Julia también 
convierte al 'nosotros, los cursillistas', en el nudo que entrelaza toda su reformulación del grupo: por ejemplo, más adelante le consulto qué quiere decir con 'sentirse parte' hoy y me informa que "nos tratan de locos cuando nos ven a los abrazos y los besos".

\section{Las sociabilidades de los Cursillos de Cristiandad de Santa Fe con su entorno católico}

Vimos recién que los lazos entablados dentro de los Cursillos de Cristiandad de Santa Fe se caracterizan por cómo son construidos por los entrevistados: más desde el 'nosotros' que a partir del 'yo'. A fin de aproximarnos a un mejor entendimiento de ese 'nosotros, los cursillistas'; continuaré examinando el relato de los informantes, pero atendiendo ahora a la forma en que diseñan los vínculos con su campo eclesial.

\section{Los vínculos eclesiales de los Cursillos de Santa Fe acorde con los entrevistados}

"Nosotros le damos cursos a la gente", afirma Pedro sobre el cursillo en sí. El retiro implica unos subgrupos o unas "mesas de trabajo"; en las cuales se conversa el cristianismo comunicado en las exposiciones o los "rollos". Las presentaciones, hechas por los participantes con trayectorias más arraigadas, y los diálogos, mantenidos en los círculos reducidos entre los nuevos involucrados; más que especulaciones acarrearían testimonios cristianos. Las experiencias en Cristo, explica Pedro, convierten a los Cursillos de Cristiandad en un movimiento pionero de la institución católica: "en la Iglesia, después, han aparecido cualquier cantidad de movimientos parecidos".

Felipe, justamente, dice que los Cursillos inspiraron al Encuentro de Cristiandad, el movimiento del cual él mismo fue el conductor principal. Su dirección del Encuentro le habría permitido tener una vivencia colectiva en un grupo de la Iglesia; aunque solo fuera como conducción compartida del círculo, y no también como puesta en común de la cotidianeidad. A la experiencia de apertura del día a día, al otro la habría 
GiUPPonI, Germán - “'Los Cursillos de Cristiandad...”

encontrado en los Cursillos, cuando comenzó a participar de la reunión de grupo y las ultreyas. Pero su hallazgo de la "experiencia comunitaria" no se limita a él mismo, sino que también se extiende hacia los demás: la ve, ante todo, en los protagonistas de las mesas del cursillo; quienes a diario quizás "no tienen nada de común" y, no obstante, en el retiro logran una "experiencia de unidad". Las vivencias colectivas parecen ser los indicios que lo llevan a inferir que el movimiento es trascendental: "hay algo que trasciende en todo eso".

Quienes también se han involucrado y continúan involucrándose en otros grupos de Iglesia son María y Susana. María fue catequista de una parroquia $\mathrm{y}$, desde hace muchos años, es tesorera de una organización para jóvenes en riesgo que tiene su sede en la ciudad de Santo Tomé: "La casa de Francisco". Susana, por su parte, hoy está inserta en un movimiento contenido en la "Orden de Agustinos Recoletos" de Santa Fe. María y Susana se refieren a los otros círculos en los cuales en paralelo se implican con un tono que es bastante respetuoso; pero que no llega nunca a ser tan cálido como cuando se remiten a los propios Cursillos. María, por ejemplo, primero comenta: “el que, digamos, a mí más me llega y el que me permite crecer, como persona y como cristiana, es el apostolado acá adentro, de las estructuras del movimiento"; para después concluir: "como he probado otros apostolados, te puedo decir que el que nunca dejé, el que nunca cambiaría, es el del movimiento". Susana, de igual forma, entre otras cuestiones cuenta: "vos ya sos 'de colores' y ya estás íntimo, parece, con el otro. Que no pasa en otros lugares. Mirá que yo he estado en muchos grupos. Estoy en distintos grupos. Pero no pasa lo mismo". María y Susana, como se ve, describen a los Cursillos como un movimiento irremplazable y especial.

Tomás, en cambio, nunca participó de otro grupo eclesial que no sean los Cursillos. El movimiento es un círculo que él conoce desde muy

6. El 'de colores' puede ser interpretado como un enunciado equivalente al 'nosotros, los cursillistas': en cuanto otra manera advertida o inadvertida mediante la que cada protagonista se identifica con el otro. 
joven, en cuanto su padre, su madre y su tío están involucrados allí desde hace mucho. Cuando acudió a su retiro, sin embargo, se sintió sorprendido; al igual que cuando entró a un equipo de cursillo. Su inserción hoy en día es tal que caracteriza al movimiento como único.

Se arma un equipo que es una cosa que no se vive en otro lado. Yo, por lo menos, no he vivido en ningún otro lado. Ni con amigos. Ni, te diría más, ni con, por ahí, la propia familia, que a uno, por ahí, le cuesta contar. Y hay cosas que vos ahí las contás. [...]. Se logra tal clima que vos hasta te sorprendés, porque hacés cosas que vos, por ahí, no harías en otro lugar o de otra forma.

Julia sí se implicó en otro grupo, a través de la catequesis. Pero su participación siempre fue muy débil; y no solo en el otro círculo, sino también en toda la institución. El compromiso de su involucramiento cambió desde que asistió a su cursillo y, en especial, al ingresar a un equipo de jornada de metodología; llegando a tener una inserción tan fuerte que, en la actualidad, reconstruye al movimiento como excepcional.

Nos vemos, nos abrazamos, nos besamos. Quedó un cariño. Parecemos locos cuando nos encontramos con los del equipo. Porque te abrazás, te besás. Y la gente, si entra $[\ldots]$ a una ultreya, dice: "estos están todos locos. Es una secta". Pero no. Es un cariño que va más allá de no sé...es inexplicable.

La excepcionalidad que Julia le adjudica a los Cursillos se enlaza con la unicidad que le atribuye Tomás; el perfil especial e irremplazable que le conceden Susana y María; y el sello trascendente y pionero que le otorgan Felipe y Pedro. Los entrevistados, con estas calificaciones, insinúan que el 'nosotros, los cursillistas', no es para ellos un 'nosotros' católico más, sino uno muy importante; incluso, el más relevante, que cuenta con una mayor estimación que los 'ellos' que lo rodean. El 'ellos, los otros católicos', es particularmente una manifestación más o menos textual o sobreentendida que también permea lo dicho por los informantes; y que, aunque no aparece como carente de consideración, sí lo hace con una apreciación menor que el mismo 'nosotros'. 
GiUPPonI, Germán - “'Los Cursillos de Cristiandad...”

\section{El comunitarismo de los Cursillos de Cristiandad}

Acabamos de ver que los entrevistados diseñan los vínculos de los Cursillos de Cristiandad de Santa Fe con su campo eclesial de una forma peculiar: exaltando el 'nosotros' ante el 'ellos'. El 'nosotros, los cursillistas', predominante en la palabra de los informantes; deviene un 'nosotros' encumbrado frente al 'ellos, los no cursillistas'.

El predominio del 'nosotros, los cursillistas' en el discurso de los entrevistados sobre las socializaciones en el seno de los Cursillos de Cristiandad nos permite sacar una primera conclusión. Esa preponderancia muestra que los participantes de los Cursillos creen ser partes de un todo; o que adscriben y pertenecen a los mismos Cursillos, conformando, en definitiva, una comunidad. La comunidad cursillista es un grupo construido por sus involucrados desde la pertenencia (Weber, 2008); o bien, a partir de una socialización intersubjetiva, sentida recíprocamente o centrada en adscripciones propias y ajenas (Simmel, 2014). La adscripción al colectivo es la concepción de que cada cual es, con el otro protagonista, partícipe de una totalidad: es el decir 'nosotros' una y otra vez (Elias, 2016).

Pero, en el relato de los informantes acerca de las sociabilidades con su entorno católico, este 'nosotros, los cursillistas' recibe un encumbramiento ante el 'ellos, los no cursillistas'. Lo cual nos habilita a extraer una segunda consecuencia del análisis realizado. Ese enaltecimiento exhibe que los cursillistas se idean que el todo del cual creen ser partes es un grupo que se distingue de su campo eclesial. Es decir, no solo adscriben a los Cursillos, sino que también los valoran frente a los otros actores eclesiásticos. O, además de pertenecer a ellos, los ven como virtuosos respecto a los demás círculos de la institución. En síntesis, aunque constituyen una comunidad, en paralelo hacen que una de sus características fundamentales sea lo que podemos llamar "comunitarismo" (Hervieu-Léger, 2005; Giménez Béliveau, 2016). El comunitarismo cursillista es una posición diseñada por los participantes de los Cursillos a la luz de la virtud. Esto es, sobre la base de una valoración de la propia comunidad entre los diferentes colectivos de la Iglesia con los cuales so- 
ciabiliza. Concretamente, la valoración del grupo es la lectura de que la totalidad de la que cada cual, con el otro involucrado, se siente partícipe; es un círculo que está por encima de los que están a su alrededor. Es el poner al 'nosotros' arriba del 'ellos'.

Ahora bien, una posición como la de los Cursillos de Cristiandad difícilmente podría ser tolerada por la cúpula de una institución como la católica. Aunque la Iglesia ya no tiene la misma incidencia sobre los católicos en general; continúa siendo una organización jerárquica, la cual sigue resistiendo a los actores inherentes a su sistema que se colocan consciente o inconscientemente en su misma cima. Dada esta situación, entonces, no sorprende que ya en 1956 Jesús Enciso Viana, el nuevo obispo de Mallorca, detuviera las primeras obras de los Cursillos. Ni que recién en el 2014 el por entonces Consejo Pontificio para los Laicos promulgara el decreto de su reconocimiento canónico definitivo. $\mathrm{Ni}$ tampoco que no sea su seno en sí mismo, sino su Organismo Mundial, lo que esa norma eclesial contempla hoy en día. Interpretación que, en última instancia, justifica que derivemos otra inferencia como respuesta tentativa a la pregunta planteada en la introducción: uno de los aspectos que configuran las socializaciones constitutivas del movimiento y que pueden convertirse en retos eclesiales es su comunitarismo.

\section{Bibliografía}

CRESPO, C. (2007) Orígenes de Cursillos de Cristiandad: la diócesis de Morón. Ponencia presentada en las VII Jornadas de Sociología, Facultad de Ciencias Sociales, Universidad de Buenos Aires, Buenos Aires.

ELIAS, N. (2016). Establecidos y marginados. Una investigación sociológica sobre problemas comunitarios [1965], Fondo de Cultura Económica, México.

GIMÉNEZ BÉLIVEAU, V. (2016). Católicos militantes. Sujeto, comunidad e institución en la Argentina, Eudeba, Buenos Aires.

GIORGI, G. y F. MALLIMACI (2012). “Catolicismos, nacionalismos y 
GiUPPONI, Germán - “'Los Cursillos de Cristiandad...”

comunitarismos en política social. Redes católicas en la creación del Ministerio de Bienestar Social de Argentina", en Revista Cultura y Religión, vol. 6, № 1, pp. 113-144.

HERVIEU-LÉGER, D. (2005). La religión, hilo de memoria [1993], Herder, Barcelona.

LUDUEÑA, G. (2014). "Ritual, narrativa e imaginación religiosa descentrada en espiritualidades católicas contemporáneas. Una mirada desde la periferia”, en Miríada, № 10, pp. 89-114.

SIMMEL, G. (2014). Sociología: estudios sobre las formas de socialización [1908], Fondo de Cultura Económica, México.

SONEIRA, J. (1999). “QQuiénes son los carismáticos? La Renovación Carismática en la Argentina”, en Sociedad y Religión, No 18/19, pp. 86-106.

SUÁREZ, A. (2014). "Nuevos movimientos y comunidades eclesiales "católicas’ ¿Qué renuevan?”, en Sociedad y Religión, No 42, pp. 92-131.

WEBER, M. (2008). Economía y sociedad. Esbozo de sociología comprensiva [1922], Fondo de Cultura Económica, México.

\section{Fuentes documentales}

BONNÍN AGUILÓ, E. y M. FERNÁNDEZ (1971). El cómo y el porqué [1955], Euramérica, Madrid.

DE COLORES (2013, abril), No 426, pp. 4-7.

$$
\text { (2014, agosto), No 442, pp. 18-19. }
$$

HERVÁS BENET, J. (1968). Manual de dirigentes de Cursillos de Cristiandad [1962], Euramérica, Madrid.

Recibido: 09/09/2017

Evaluado: 24/11/2017

Versión final: 15/02/2018 